\title{
Experimental and numerical analysis of high and low velocity impacts against neat and shear thickening fluid (STF) impregnated weave fabrics
}

\author{
Djalel Eddine Tria ${ }^{1, *}$, Larbi Hemmouche ${ }^{1}$, Abdelhadi Allal $^{1}$ and Abdelkader Benouali ${ }^{2}$ \\ ${ }^{1}$ Military Polytechnic School, BP17, Algiers, Algeria \\ ${ }^{2}$ Military University of Technology, Gen. Sylwest. Kalis., 00-908 Warsaw, Poland
}

\begin{abstract}
This investigation aims to study the efficiency of STF impregnated plain-weave fabric made of Kevlar under high and low velocity impact conditions. The shear thickening fluid (STF) was prepared by ultrasound irradiation of silica nanoparticles (diameter $\approx 30 \mathrm{~nm}$ ) dispersed in liquid polyethylene glycol polymer. STF impregnation effect was determined from single yarn pull-out test and penetration at low velocity using drop weight machine equipped with hemi-spherical penetrator and dynamic force sensor. Force-displacement curves of neat and impregnated Kevlar were analysed and compared. Also, the STF impregnation effect on Kevlar multilayers was analysed from high velocity impact tests using 9mm FMJ bullet at $390 \mathrm{~m} / \mathrm{s}$. After impact, Back face deformation (BFD) of neat and impregnated Kevlar layers were measured and compared. Results showed that STF impregnated fabrics have better energy absorption and penetration resistance as compared to neat fabrics without affecting the fabric flexibility. When relative yarn translations are restricted (e.g. at very high levels of friction), windowing and yarn pull-out cannot occur, and the fibres engaged with the projectile fail in tension that leads to fabric penetration. Microscopy of these fabrics after testing have shown pitting and damage to the Kevlar filaments caused by the hard silica particles used in the STF. Mesoscopic 3D Finite Element models were developed using explicit LS-DYNA hydrocode to account for STF impregnation by employing the experimental results of yarn pull-out tests, low and high velocity impacts. It was found that friction between fibers and yarns increase the dissipation of energy upon impact by restricting fiber mobility, increasing the energy required for relative yarn translations and transferring the impact energy to a larger number of fibers.
\end{abstract}

\section{Introduction}

Kevlar fabrics were developed in demanding of several applications due to their low density combined with high strength, toughness and thermal stability. For the protection against ballistic threats, Kevlar woven fabrics offer a limited protection level. Therefore, recent works are involving into a different means to enhance their mechanical behaviour against such loading. The impregnation of Non-Newtonian fluids into weave fabrics has drawn attention because of their role in energy absorption induced by impact phenomena.

In this study, we focus about the use of Shear Thickening Fluid (STF) as an enhancement agent.

Complete experimental and numerical investigations were conducted in order to understand the mechanical behaviour of neat and impregnated Kevlar. In order to understand how the STF impregnation plays a role in energy absorption, a mesoscopic study of the Kevlar fabrics were performed. A serial of mechanical tests on single yarns and plain weave fabrics were made. Then, impact tests at low and high velocity were performed using drop weight tour and $9 \mathrm{~mm}$ FMJ bullet successively. Also, detailed Finite Element models at mesoscopic scale have been carried out to understand the ballistic mechanisms of neat fabrics and STF impregnation.

\section{Materials characterization}

\subsection{Orthotropic behaviour of plane weaves fabric}

Quasi-static tensile tests were carried out on Kevlar fabric using a universal tensile machine equipped with a high sensitivity extensometer (Fig.1).

Figure 2 presents specimens after tensile tests in warp $\left(0^{\circ}\right)$, weft $\left(90^{\circ}\right)$ and $45^{\circ}$ directions. Stress-strain curves are presented in Fig. 3, 4 and 5.

Mechanical properties of Kevlar 29 weave fabric in all directions are presented in Table 1 and 2.

\footnotetext{
Corresponding author: djaleleddine.tria@gmail.com
} 


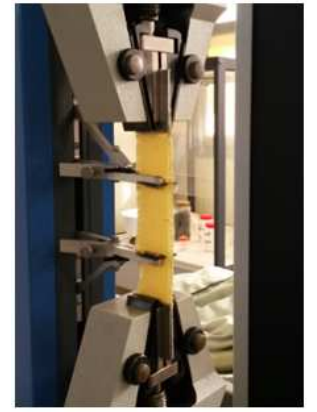

(a)

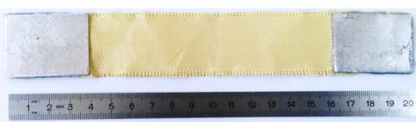

Fig. 1. Tensile tests on Kevlar 29 fabric in (a) warp and (b) weft directions.

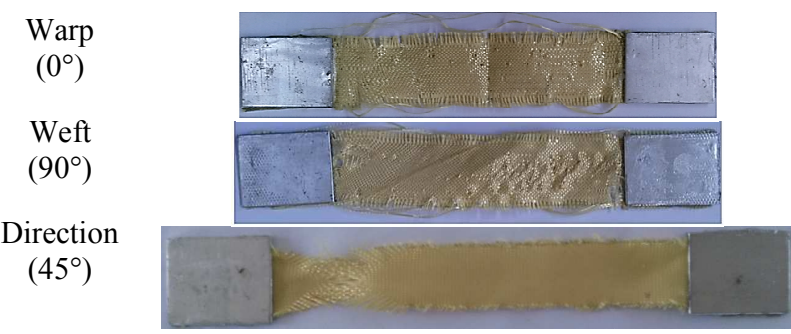

Fig. 2. Tensile specimens after tests.

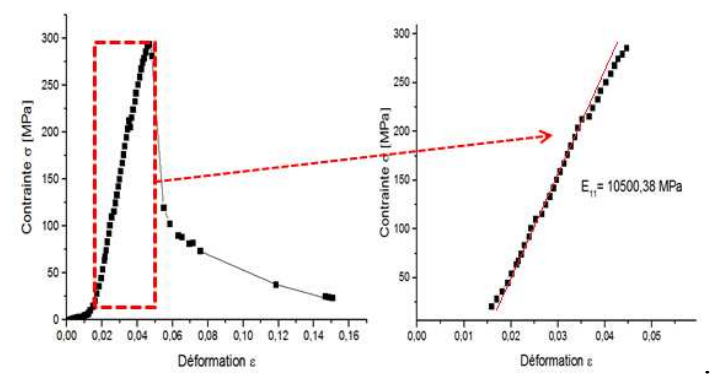

Fig. 3. Stress-strain curve on Kevlar 29 in warp direction.

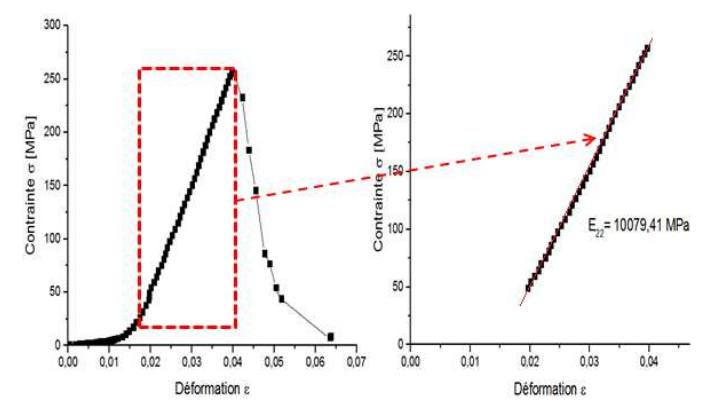

Fig. 4. Stress-strain curve in weft direction.

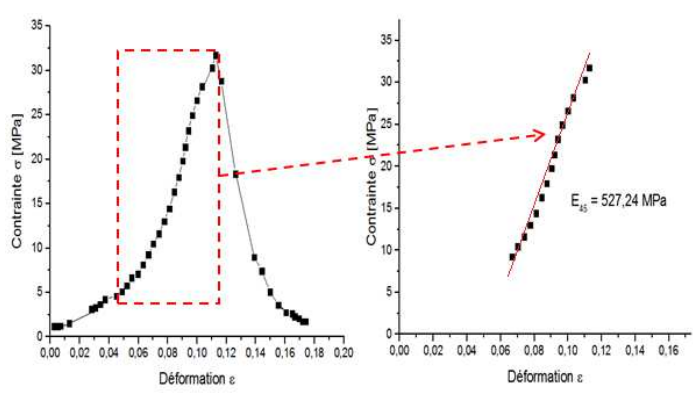

Fig. 5. Stress-strain curve in $45^{\circ}$ direction.

Table 1. Mechanical properties of Kevlar 29 along warp and welf directions.

\begin{tabular}{|c|c|c|c|c|}
\hline & $\mathbf{E}[\mathbf{M P a}]$ & $\boldsymbol{\sigma}_{\mathbf{R}}[\mathbf{M P a}]$ & $\boldsymbol{\varepsilon}_{\mathbf{R}}$ & $\mathbf{A}[\mathbf{\%}]$ \\
\hline Warp direction & 10500.38 & 294.06 & 0.0466 & 4.66 \\
\hline Weft direction & 10079.41 & 257.14 & 0.0396 & 3.96 \\
\hline
\end{tabular}

Table 2. Mechanical properties of Kevlar 29 along $45^{\circ}$ direction.

\begin{tabular}{|c|c|c|c|c|c|}
\hline & $\begin{array}{c}\boldsymbol{E}_{45} \\
{[\mathbf{M P a}]}\end{array}$ & $\begin{array}{c}\boldsymbol{G}_{12} \\
{[\mathbf{M P a}]}\end{array}$ & $\begin{array}{c}\boldsymbol{\sigma}_{45 \mathrm{R}} \\
{[\mathbf{M P a}]}\end{array}$ & $\begin{array}{c}\gamma_{12 \mathrm{R}} \\
{[\mathbf{M P a}]}\end{array}$ & $\mathbf{A} / \%]$ \\
\hline Direction $45^{\circ}$ & 527.24 & 550.50 & 31.74 & 15.87 & 11.26 \\
\hline
\end{tabular}

\subsection{Mechanical behaviour of a single yarn}

Tensile tests were conducted on single yarn in order to study their mechanical behaviour in all directions (Fig.6). Three types of specimens were used with different initial lengths (Fig.7). Results presented in Fig.8 are used to determine the elastic parameters presented in equation (1).

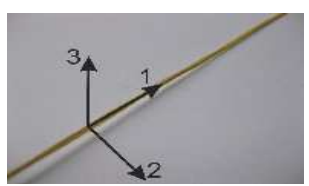

Fig. 6. Direction of yarns.

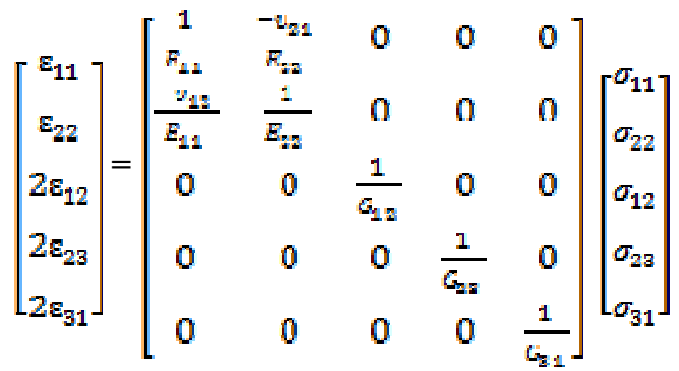



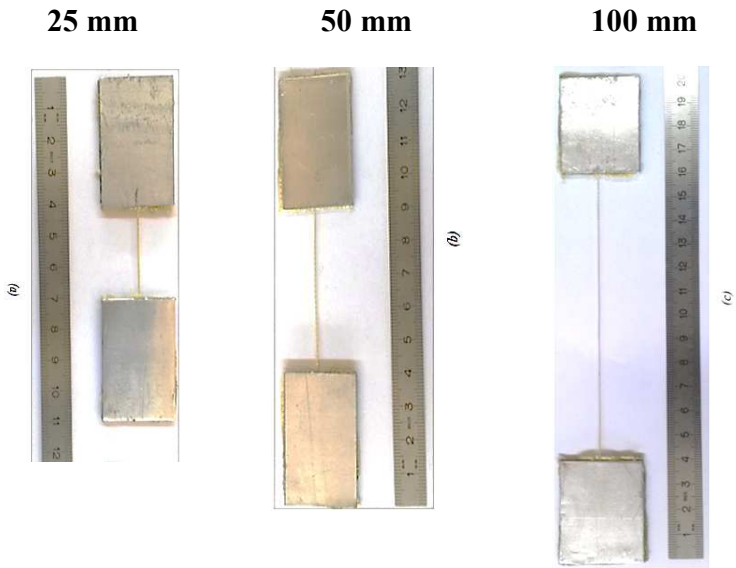

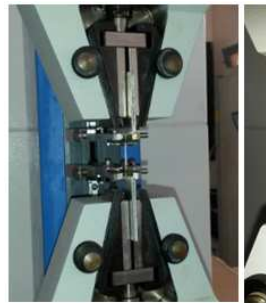

(a)

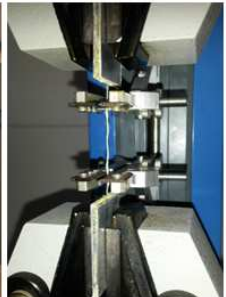

(b)

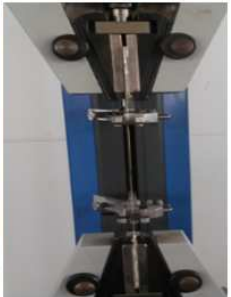

(c)
Fig. 7. Tensile test on single yarns with different initial length.
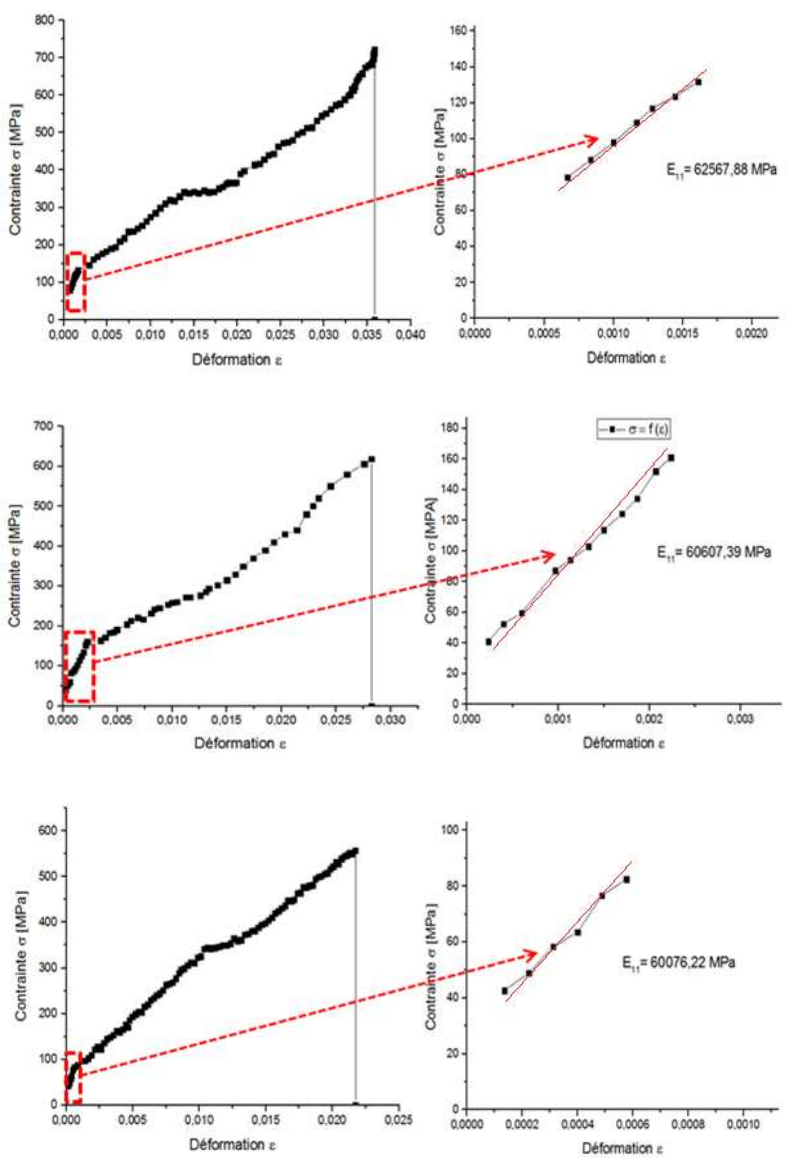

Fig. 8. Stress-strain curves of tensile tests conducted on single yarns with 25,50 and $100 \mathrm{~mm}$ length.

Table 3 summarizes the mechanical parameters of a single yarn in all directions.
Table 3. Mechanical properties of Kevlar 29 yarn for different

\begin{tabular}{|c|c|c|c|c|}
\hline Yarn length & $\mathbf{E}_{\mathbf{1 1}}[\mathbf{M P a}]$ & $\boldsymbol{\sigma}_{\mathbf{1 1 R}}[\mathbf{M P a}]$ & $\boldsymbol{\varepsilon}_{\mathbf{1 1 R}}$ & $\mathbf{A}_{\mathbf{1 1}}[\mathbf{\%}]$ \\
\hline $\mathbf{2 5} \mathbf{~ m m}$ & 62567.88 & 721.91 & 0.0358 & 3.58 \\
\hline $\mathbf{5 0} \mathbf{~ m m}$ & 60607.39 & 618.64 & 0.0282 & 2.82 \\
\hline $\mathbf{1 0 0} \mathbf{~ m m}$ & 60076.22 & 557.73 & 0.0217 & 2.17 \\
\hline
\end{tabular}

\section{Impact Tests}

\subsection{Impact tests at low velocity}

The response of neat and impregnated Kevlar fabrics at low velocity impact was carried out using a drop weigh tour, equipped with a piezoelectric sensor (Fig. 9).

Results had shown that STF impregnation influence on the impact behaviour of the fabric.

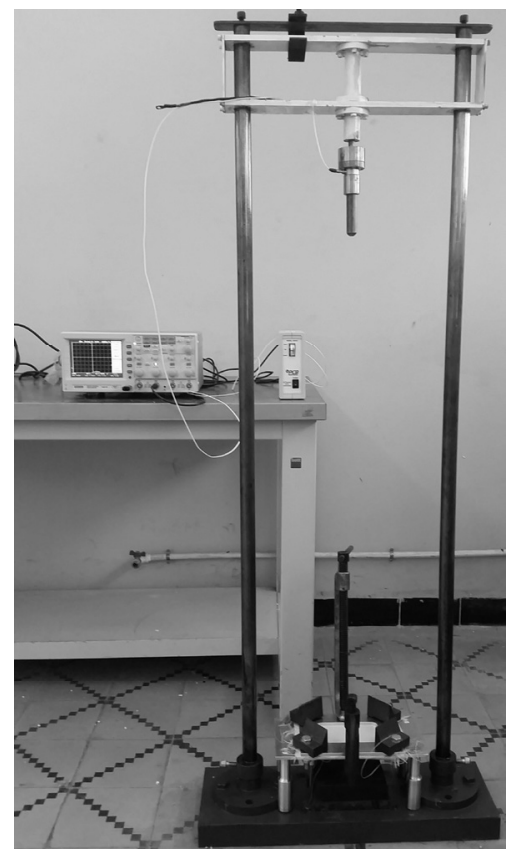

Fig. 9. Drop weight tour with hemi-spherical impactor and load cell.

Figure 10 shows neat Kevlar fabrics subjected to impact at $4.4 \mathrm{~m} / \mathrm{s}$ and $67 \mathrm{~J}$. It is clearly seen that one layer wasn't able to stop the penetrator in the case of neat Kevlar. Load history is presented in Figure 11.

\subsection{High velocity impact tests}

Plates of neat and impregnated Kevlar fabrics were prepared for high velocity ipact tests. A full metal jacketed $9 \mathrm{~mm}$ bullet were used to hit 200X200 mm plates at $390 \mathrm{~m} / \mathrm{s}$. At each test, the trauma effect was measured.

Figure 14 shows the front and the rear sides of a neat fabric plates, were damaged zones are highlighted. Test results are presented in Table 4. 

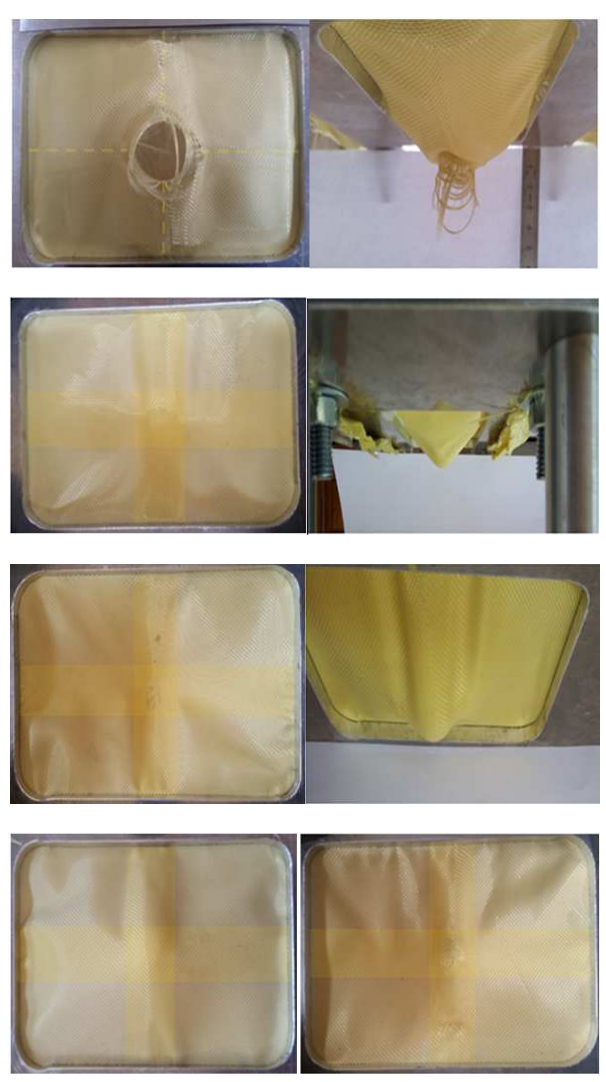

Fig. 10. Low velocity test results on single, 2, 3 and 4 layers of kevlar 24 .

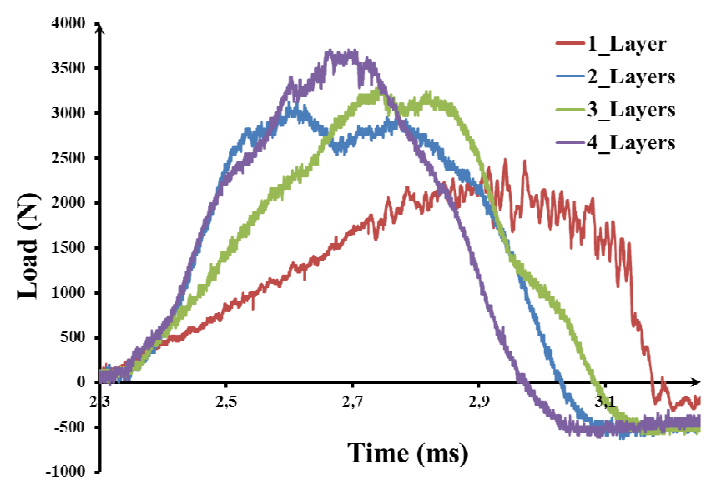

Fig. 11. Load impact history of neat kevlar 24 layers.

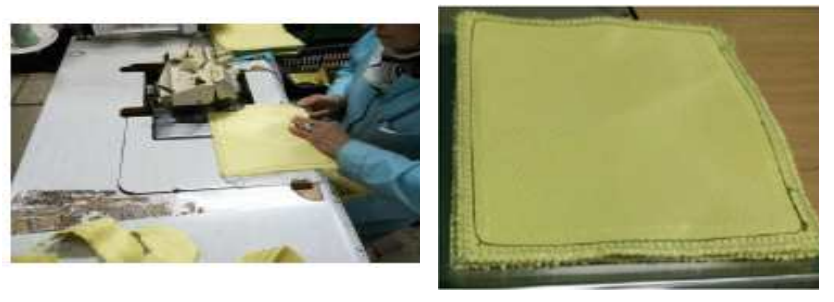

Fig. 12. Kevlar 24 plates assembly.

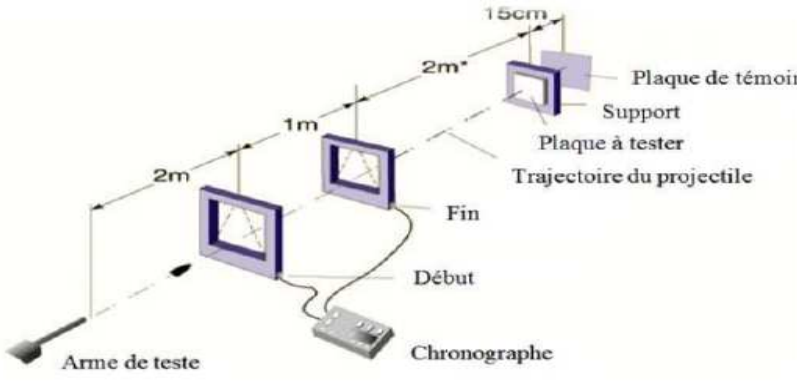

Fig. 13. Ballistic tests set-up.

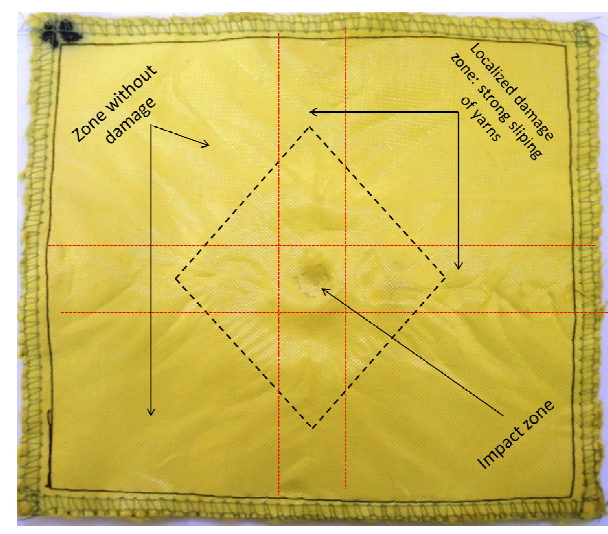

Front

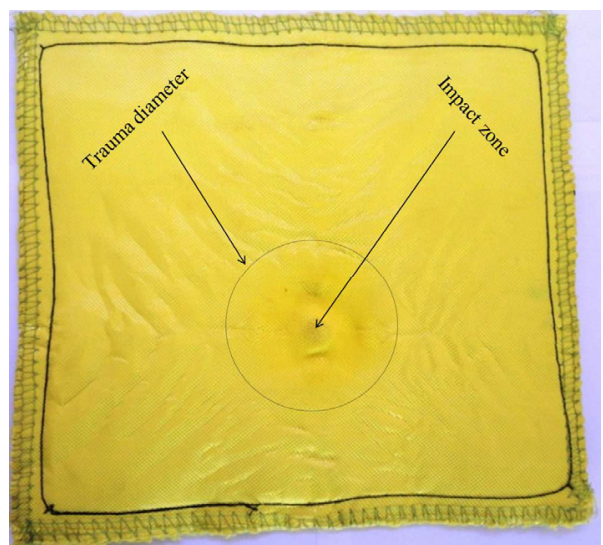

Back face

Fig. 14. Kevlar plates subjected to $9 \mathrm{~mm}$ FMJ bullet at $390 \mathrm{~m} / \mathrm{s}$.

Table 4. Experimental results for different number of layers.

\begin{tabular}{|c|c|c|c|c|}
\hline $\begin{array}{c}\text { Number } \\
\text { of } \\
\text { layers }\end{array}$ & $\begin{array}{c}\text { Initial } \\
\text { velocity } \\
\mathbf{( m / s )}\end{array}$ & $\begin{array}{c}\text { Trauma } \\
\text { effect } \\
\mathbf{( m m )}\end{array}$ & $\begin{array}{c}\text { Trauma's } \\
\text { diameter }\end{array}$ & $\begin{array}{c}\text { damaged } \\
\text { layers }\end{array}$ \\
\hline 14 & 387 & 37.7 & 46 & 0 \\
\hline 16 & 395 & 35.6 & 46.5 & 0 \\
\hline 18 & 394 & 32 & 47 & 0 \\
\hline 26 & 390 & 27.7 & 47.5 & 0 \\
\hline
\end{tabular}




\section{Computational modelling}

All the numerical simulations were carried out using the explicit Finite Element code LS-DYNA. For low velocity impact models, the weave fabric was modelled using Meso-heterogeneous approach in order to understand the effect of the STF impregnation.

However, because of processing cost, in high velocity impact models we used a macro homogeneous approach because of the high number of layers.

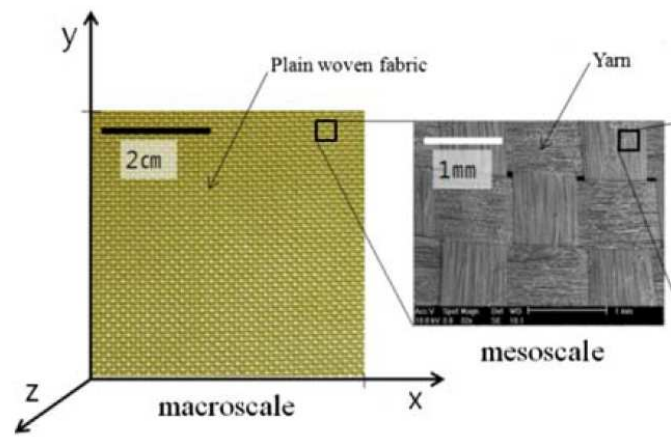

Fig. 15. Mesoscopic presentation of neat Kevlar 29 fabric.
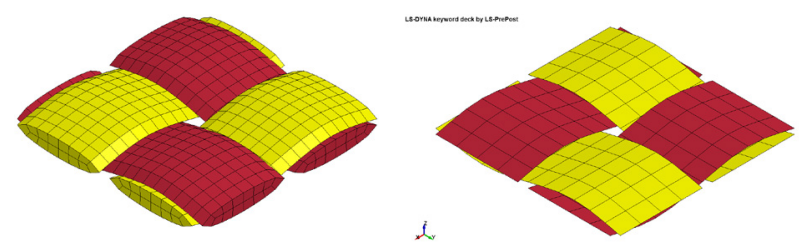

Fig. 16. Modelling of the plain weave fabric unit cell using 3D solid and Shell elements.

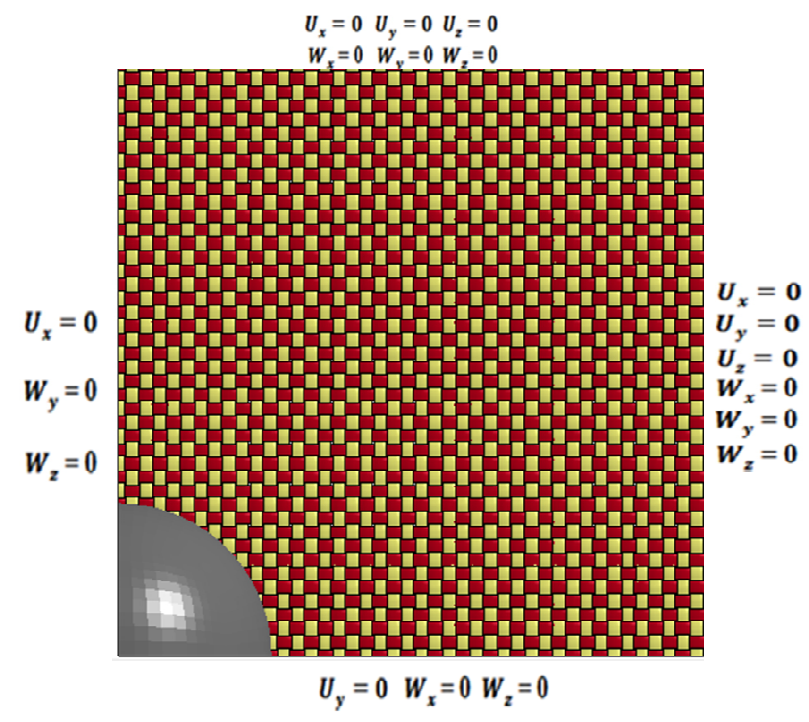

Fig. 17. Finite elements model of plain weave fabric with spherical impactor.

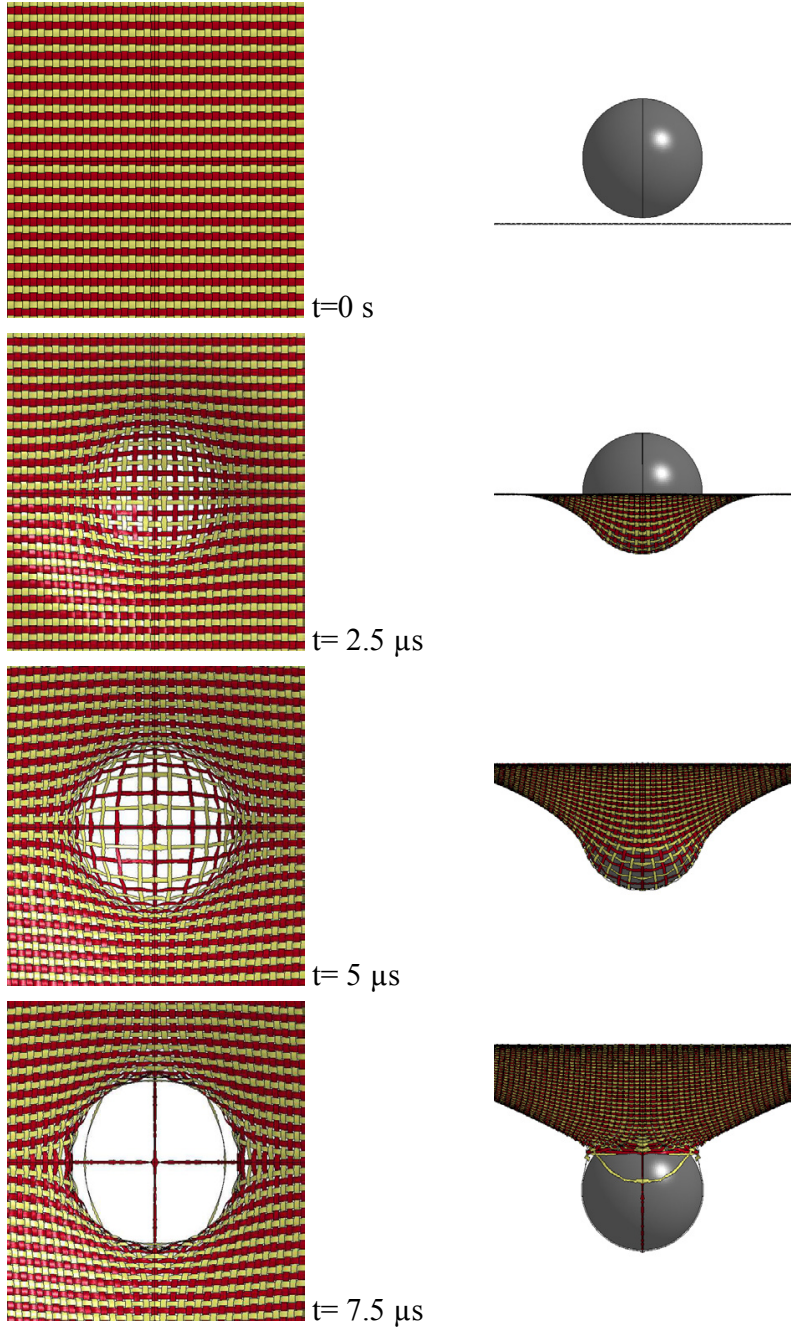

Fig. 18. Impact sequences of single plain fabric.
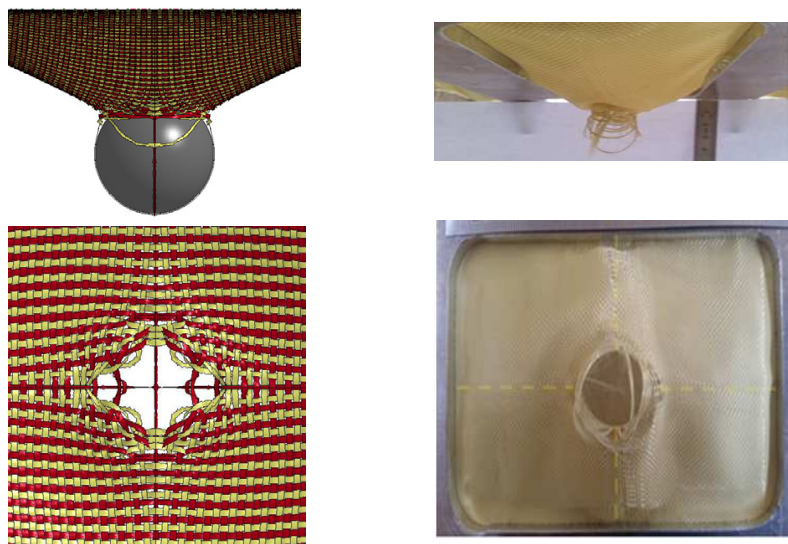

Fig. 19. Modelling versus experimental results of the plain fabric after penetration. 

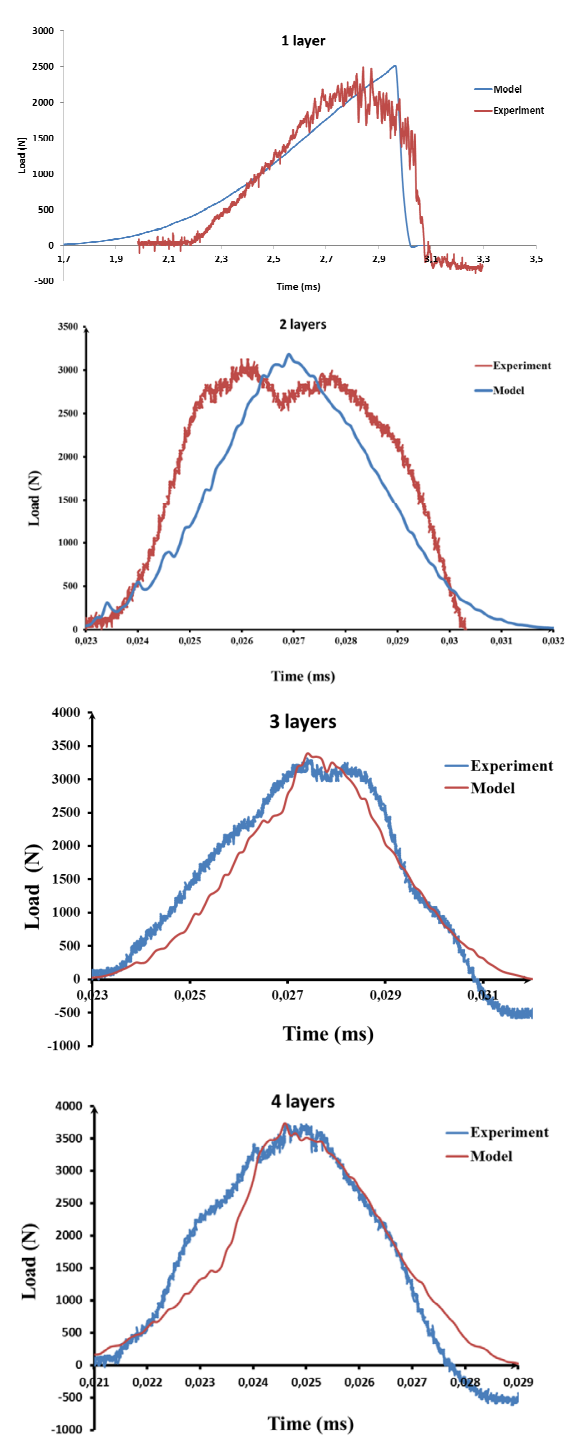

Fig. 20. Experimental and modelling results of the low impact velocity tests on plain weave fabrics.
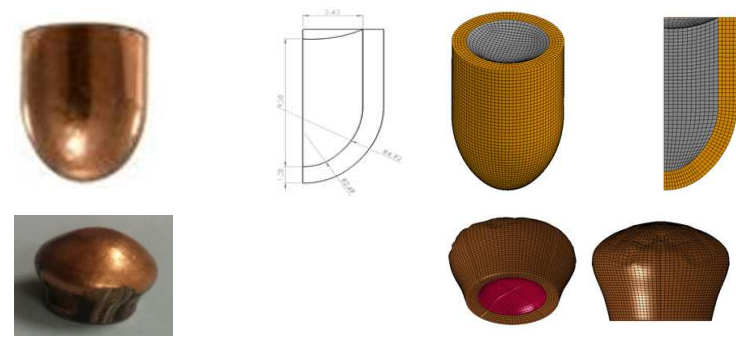

Fig. 21. Finite elements model of the $9 \mathrm{~mm}$ FMJ bullet before and after the impact tests using 3D solid element.
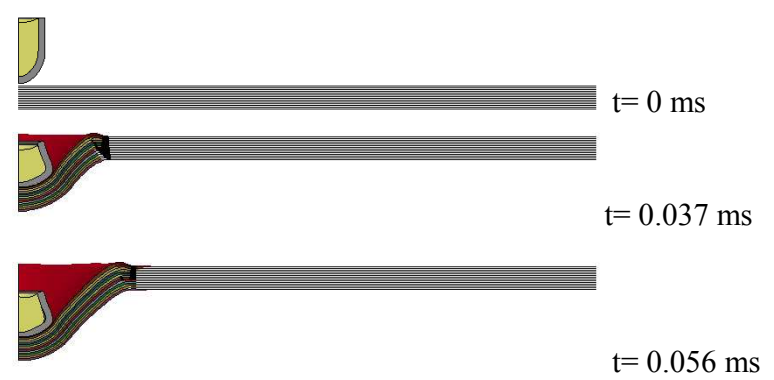

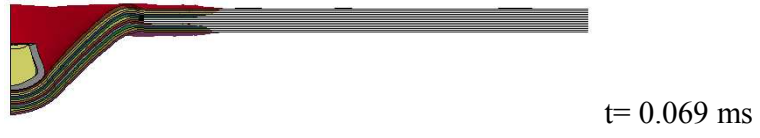

Fig. 22. Plot of impact sequences on 14 kevlar fabrics.

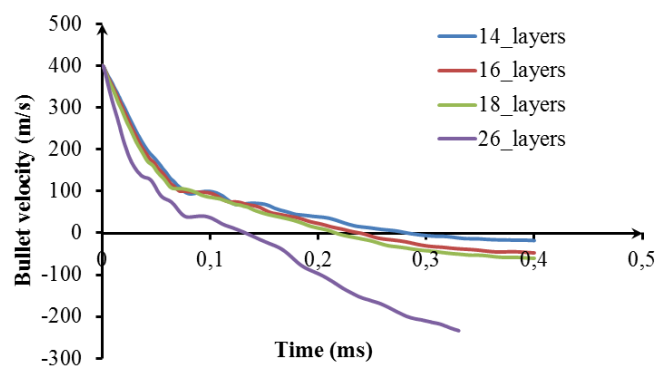

Fig. 23. Bullet velocity history.

\section{Conclusions}

This series of tensile tests, instrumented impact experiments and computational simulations, many findings can be drawn:

- When relative yarn translations are restricted (e.g. at very high levels of friction), windowing and yarn pullout cannot occur, and the fibers engaged with the projectile fail in tension that leads to fabric penetration.

- Microscopy of these fabrics after testing have shown pitting and damage to the Kevlar filaments caused by the hard silica particles used in the STF.

- Mesoscopic 3D Finite Element models were developed using explicit LS-DYNA hydrocode to account for STF impregnation by employing the experimental results of yarn pull-out tests, low and high velocity impacts.

- It was found that friction between fibres and yarns increase the dissipation of energy upon impact by restricting fibre mobility, increasing the energy required for relative yarn translations and transferring the impact energy to a larger number of fibres.

\section{References}

1. C. Ha-Minh, T. Kanit, F. Bousou, A. Imad. Comp. Mat. Sci. 50 (2011)

2. J.A. Bencomo-Cisneros, A. Tejeda-Ochoa, J.A. Gracia-Estrada. J. Alloys Compds., 5365 (2012)

3. B. Lee, C. Kim. Adv. Comp. Mat. 21(2012)

4. Y. Lee, E.D. Wetzel, N.J. Wagner, J. Mat. Sci, 38 (2003)

5. A. Srivastava, A. Majumdar, B. Butola, A review in Solid State and Material Sciences, 2012)

6. L. Wierzbicki, A. Danelska, K. Olszewska, Comp. Theo. Pract. 13:4 (2013) 